\title{
WORKSHOP
}

\section{A COMPARATIVE ANALYSIS OF 30 BONUS-MALUS SYSTEMS}

\author{
By Jean Lemaire And Hongmin ZI \\ Wharton School \\ University of Pennsylvania
}

\begin{abstract}
The automobile third party insurance merit-rating systems of 22 countries are simulated and compared, using as main tools the stationary average premium level, the variability of the policyholders' payments, their elasticity with respect to the claim frequency, and the magnitude of the hunger for bonus. Principal components analysis is used to define an "Index of Toughness" for all systems ".
\end{abstract}

\section{INTRODUCTION}

Most countries have now introduced merit-rating or bonus-malus systems (BMS) in third party liability automobile insurance rating. Such systems penalise policyholders at fault in accidents by surcharges, and reward claim-free years by discounts. This study uses simulation to compare the BMS in force in six East Asian countries (Hong Kong, Japan, South Korea, Malaysia-Singapore, Taiwan, Thailand), fourteen European countries (Belgium, Denmark, Finland, France, Germany, Italy, Luxembourg, The Netherlands, Norway, Portugal, Spain, Sweden, Switzerland, and the United Kingdom), as well as Kenya and Brazil. Several of these countries have recently modified their system. In these cases, both the old and the new BMS are studied, to investigate the impact of the recent modifications.

The regulatory environments in the selected countries are extremely diversified, from total freedom (like in the U.K., where each insurer is free to design its own BMS) to government-imposed systems (like in Switzerland, where all companies have to use the same BMS), with many intermediate situations (Denmark, for instance, where insurers apply BMS rules quite loosely). Obviously the approach to bonus-malus design depends on regulation. If a tariff is imposed by the government and every insurer has to use it, there is no commercial pressure to match the premiums to the risks by making use of every available relevant information. Supervising authorities may choose, for socio-political reasons, to exclude from the tariff structure certain risk factors, even though they may be significantly correlated to losses. The government may then seek to correct for the inadequacies of the $a$

\footnotetext{
The authors wish to express their most sincere thanks to Azleen Ahmad,Bjorn Ajne, Alain Chevreau, Ted Chung, Freddy Corlier, Thatsanee Dharmpipit, Hans Gerber, Walther Neuhaus, Meha Patel, Danny Quant, Joakim Hertig, Peter Johnson, Gi-Taig Jung, Edward Levay, Harri Lonka, Thomas Mack, Riccardo Ottaviani, Ermanno Pitacco, Shuji Naito, Roberto Westenberger, and Chen Yeh-Lai, who have kindly provided detailed information about the systems in force in their respective countries. Special thanks to Ted Chung, for providing us with extensive loss data, and to Peter Johnson, for thoughtful personal comments.
} 
priori system by using a "tough" BMS. In a free market, carriers need to use a rating structure that matches the premiums to the risks as closely as possible, or at least as closely as the rating structures used by competitors. This entails using virtually every available classification variable correlated to the risks, since failing to do so would mean sacrificing the chance to select against competitors, and incurring the risk of suffering adverse selection by them. Therefore, the use of more a priori classification variables is expected in free market countries, which decreases the need for a sophisticated BMS.

Despite these major differences in perspective, the comparison of BMS across countries may prove to be interesting, if only to allow countries to evaluate how "severe" their BMS is, compared to neighbours. This article extends and updates the results of a preceding study (LEMAIRE, 1988a), where 13 BMS were analysed. Two main reasons motivate this update:

(i) Several countries have modified their BMS since 1988, enforcing stiffer penalties in case of claims.

(ii) While the earlier study focussed on insurance companies, the emphasis of the present research is the policyholder. For instance, this research evaluates the evolution of the average premium and its variability, as a function of the policyholder's claim frequency. The earlier study evaluated the insurer's premium income, by introducing a density function for the claim frequencies in the portfolio (the structure function) as well as a model for the number of new insureds and policy terminations. The two approaches lead to very different results. In most countries the constant flow of new drivers subsidies existing policies; the average premium level in an open portfolio is higher than the expected premium paid by an average policyholder.

All BMS are summarised in the Appendix. Section 2 presents the tools used in the analysis: the relative stationary average premium level, the coefficient of variation of premiums, as a function of time and claim frequency, the elasticity of premiums with respect to claim frequency, and the average claim retention to avoid future surcharges. There is a significant positive correlation between these measures. In Section 3, factor analysis is used to summarise the data, and define an "Index of Toughness" for all systems, as the score along the first principal component. Comments for some BMS are found in Section 4.

\section{TOOLS FOR THE COMPARISON OF THE SYSTEMS}

All BMS were simulated, assuming that the number of at-fault claims for a given policyholder conforms to a Poisson distribution, with parameter $\lambda$. All values of $\lambda$ between 0 and 1 were considered. In many countries, the average claim frequency in a typical portfolio is at or below $10 \%$. This average value was selected as benchmark for summary presentations.

In a few countries, the starting class in the BMS depends on exogenous variables like the age of the driver, or the annual mileage of the car. All simulations were performed assuming a new policyholder, driving annually less than 15,000 kilometres in a passenger car, without business use. Assumptions specific to single countries are described in the Appendix. 


\section{Tool \#1 : The Relative Stationary Average Premium Level}

An apparently inescapable consequence of the implementation of a BMS is a progressive decrease of the observed average premium level, due to a concentration of policyholders in the high-discount classes. With claim frequencies averaging $10 \%$ or less, it would be necessary to penalise each claim by nine classes to maintain a balanced distribution of policyholders among the classes. Because such severe penalties seem commercially impossible to enforce, most policies tend to cluster in the lowest BMS classes.

For all systems, the average premium level of a policyholder with claim frequency $10 \%$ was simulated for 30 years, the maximum period most BMS seem to take a reach stationarity. Figure 1 presents the evolution of the mean premium

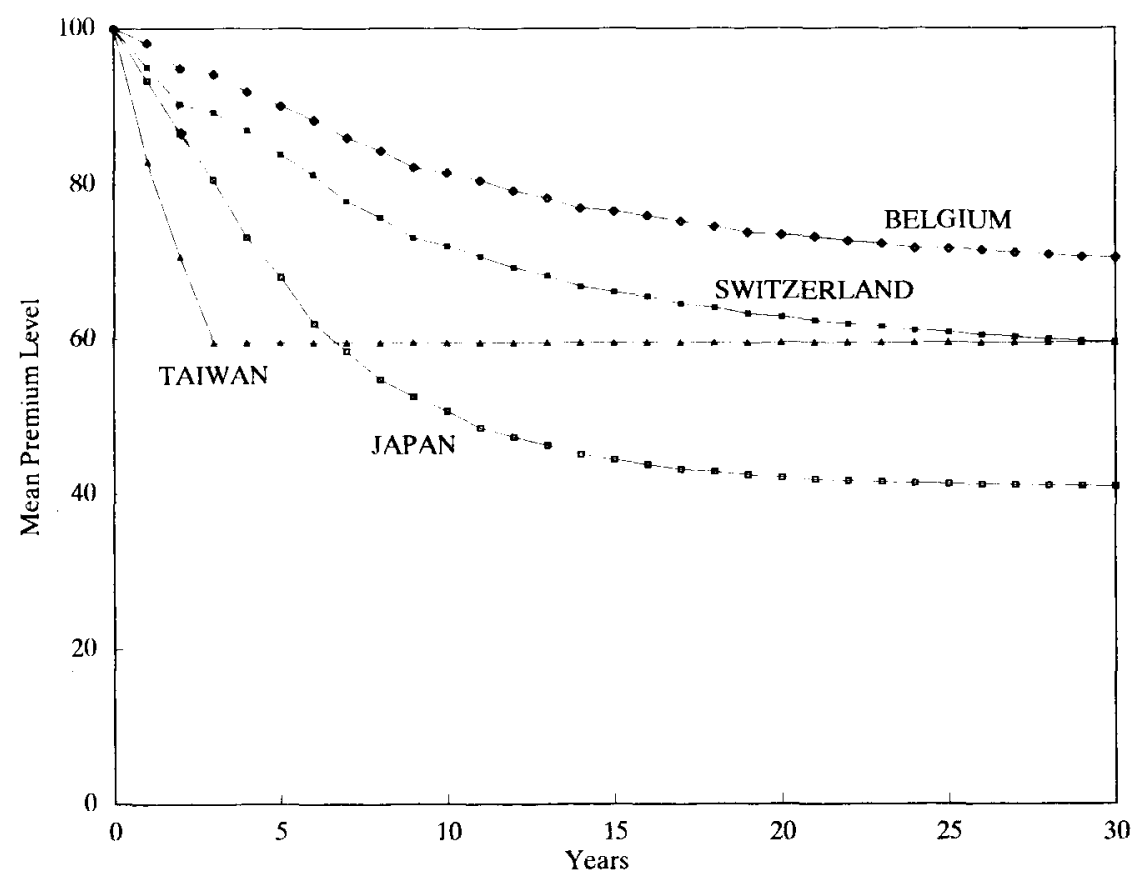

Figure 1. Evolution of mean level.

level for the selected countries. For a simple system like the Taiwanese, the premium decreases abruptly in the first few years, the time it takes for the best policyholders to reach the highest discount. The system then stabilises rapidly. For the more "sophisticated" systems the premium decreases in a much smoother way, and the steady state is not reached until at least 30 years have elapsed.

Given the wide variety of systems in force, stationary average levels are difficult to compare. Therefore, a "Relative Stationary Average Level" (RSAL) was defined as

RSAL $=\frac{\text { stationary average level }- \text { minimum level }}{\text { maximum level }- \text { minimum level }}$ 
Expressed as a percentage, this is an index that determines the relative position of the average policyholder, when the lowest premium is set equal to zero and the highest to 100 . A low value of RSAL indicates a high clustering of policies in the lowest BMS classes. A high RSAL suggests a better spread of policies among classes. Table 1 ranks all systems according to the RSAL. The top three countries on this list have very simple, bonus-only, systems: in case of a claim, a policyholder loses the entire discount accumulated over several years.

TABLE 1

Relative Stationary Average Level for all systems

\begin{tabular}{|c|c|c|}
\hline Rank & Country & RSAL \\
\hline 1 & Kenya & $28.79 \%$ \\
\hline 2 & Spain & $25.67 \%$ \\
\hline 3 & Malaysia & $21.17 \%$ \\
\hline 4 & Finland (new) & $16.04 \%$ \\
\hline 5 & Sweden & $14.20 \%$ \\
\hline 6 & Netherlands & $11.78 \%$ \\
\hline 7 & U.K. (protected) & $11.37 \%$ \\
\hline 8 & Taiwan & $9.55 \%$ \\
\hline 9 & Finland (old) & $8.46 \%$ \\
\hline 10 & Hong Kong & $8.35 \%$ \\
\hline 11 & Thailand & $8.03 \%$ \\
\hline 12 & U.K. (unprotected) & $7.07 \%$ \\
\hline 13 & Portugal & $6.75 \%$ \\
\hline 14 & Norway (old) & $6.61 \%$ \\
\hline 15 & Switzerland (new) & $6.47 \%$ \\
\hline 16 & Germany (new) & $5.85 \%$ \\
\hline 17 & Japan (new) & $4.63 \%$ \\
\hline 18 & Belgium (new) & $4.05 \%$ \\
\hline 19 & Denmark & $3.78 \%$ \\
\hline 20 & Switzerland (old) & $2.90 \%$ \\
\hline 21 & France & $2.12 \%$ \\
\hline 22 & Norway & $2.11 \%$ \\
\hline 23 & Brazil & $1.85 \%$ \\
\hline 24 & Korea & $1.37 \%$ \\
\hline 25 & Luxembourg (new) & $1.36 \%$ \\
\hline 26 & Italy (new) & $1.30 \%$ \\
\hline 27 & Luxembourg (old) & $1.01 \%$ \\
\hline 28 & Japan (old) & $0.88 \%$ \\
\hline 29 & Belgium (old) & $0.74 \%$ \\
\hline 30 & Italy (old) & $0.01 \%$ \\
\hline
\end{tabular}

Note: In theory, the value of the RSAL cannot be computed for Norway, as there is no maximum premium level. In practice, however, very few policyholders have more than three claims in a given year: the probability that a driver with claim frequency 0.10 has 4 or more claims in a year is $3.8 \times 10^{-6}$. Therefore, high-malus classes in Norway are very sparsely populated, all the more so as malus evasion seems to be tolerated by insurers. It was therefore assumed that no driver can have a malus exceeding three claims above starting level.

All BMS carry an implicit penalty for new drivers, since the premium level of the access class is substantially higher than the average stationary premium level. Table 2 ranks all systems according to this first-year surcharge. 
TABLE 2

IMPLICIT SURCHARGE FOR NEWCOMERS

\begin{tabular}{|c|c|c|}
\hline Rank & Country & Surcharge \\
\hline 1 & Germany (new) & $+212.97 \%$ \\
\hline 2 & Norway (new) & $+195.80 \%$ \\
\hline 3 & Denmark & $+189.50 \%$ \\
\hline 4 & Norway (old) & $+159.13 \%$ \\
\hline 5 & Sweden & $+158.89 \%$ \\
\hline 6 & Netherlands & $+146.29 \%$ \\
\hline 7 & Japan (old) & $+144.12 \%$ \\
\hline 8 & Finland (old) & $+143.39 \%$ \\
\hline 9 & Finland (new) & $+142.57 \%$ \\
\hline 10 & Korea & $+135.51 \%$ \\
\hline 11 & Hong Kong & $+122.04 \%$ \\
\hline 12 & Japan (new) & $+121.76 \%$ \\
\hline 13 & Italy (new) & $+121.38 \%$ \\
\hline 14 & Luxembourg (new) & $+100.89 \%$ \\
\hline 15 & U.K. (unprotected) & $+98.75 \%$ \\
\hline 16 & Switzerland (old) & $+94.10 \%$ \\
\hline 17 & Luxembourg (old) & $+92.25 \%$ \\
\hline 18 & U.K. (protected) & $+84.65 \%$ \\
\hline 19 & France & $+77.55 \%$ \\
\hline 20 & Malaysia & $+76.65 \%$ \\
\hline 21 & Kenya & $+74.60 \%$ \\
\hline 22 & Taiwan & $+68.20 \%$ \\
\hline 23 & Switzerland (new) & $+67.88 \%$ \\
\hline 24 & Italy (old) & $+64.26 \%$ \\
\hline 25 & Brazil & $+52.33 \%$ \\
\hline 26 & Thailand & $+50.55 \%$ \\
\hline 27 & Belgium (new) & $+41.87 \%$ \\
\hline 28 & Belgium (old) & $+39.26 \%$ \\
\hline 29 & Spain & $+28.70 \%$ \\
\hline 30 & Portugal & $+26.95 \%$ \\
\hline
\end{tabular}

Several countries at the bottom of the list have, in addition to these implicit increases, explicit penalties for inexperienced drivers: surcharges in France, a deductible after a claim in Belgium and Switzerland. Of course the implicit surcharge for new drivers is not related to the overall toughness of the system; it is a measure of the degree of cross-subsidization between young and experienced drivers.

\section{Tool \#2: The coefficient of variation of the insured's premiums}

Insurance consists in a transfer of risk from the policyholder to the carrier. Without experience rating, the transfer is total (perfect solidarity): the variability of insureds' payments is zero. With experience rating, personalised premiums from the policyholder will vary from year to year according to claims history; cooperation between drivers is weakened. Solidarity between policyholders can be evaluated by a measure of the variability of annual premiums. The coefficient of variation (standard deviation divided by mean) was selected, as it is a dimension-less parameter. There is thus no need for currency conversions.

The Actuarial Institute of the Republic of China kindly provided us with market-wide observed loss distributions, property damage and bodily injury, for 
accident years 1987 to 1989 . These distributions are very well represented by a Log-normal model (LemAIRE, 1993). Assuming that the aggregate claims process is Compound Poisson with Log-normal severities (Bowers et al., 1986, chapter 11), its coefficient of variation is found to average 6.40. While loss distributions in other countries of course differ from the Taiwanese experience, the coefficient of variation is not likely to be affected much.

Table 3 ranks all countries according to the stationary coefficient of variation of payments, for a policyholder with claim frequency 0.10 . These figures are divided by 6.40 in the last column, to indicate the percentage of the original coefficient of variation retained by the policyholder. They show that, even for the most severe systems, insureds are only asked to carry a small part of the variability of the process, $7.18 \%$ for the new Swiss system, on top of the list.

TABLE 3

COEFFICIENT OF VARIATION OF PREMIUMS

\begin{tabular}{|c|c|c|c|}
\hline Rank & Country & Coef. of variation & Percentage retained \\
\hline 1 & Switzerland (new) & 0.4595 & $7.18 \%$ \\
\hline 2 & Norway (old) & 0.3900 & $6.09 \%$ \\
\hline 3 & Kenya & 0.3835 & $5.99 \%$ \\
\hline 4 & Finland (new) & 0.3834 & $5.99 \%$ \\
\hline 5 & Sweden & 0.3769 & $5.89 \%$ \\
\hline 6 & Netherlands & 0.3523 & $5.50 \%$ \\
\hline 7 & Japan (new) & 0.3283 & $5.13 \%$ \\
\hline 8 & Taiwan & 0.3162 & $4.94 \%$ \\
\hline 9 & Malaysia & 0.3075 & $4.80 \%$ \\
\hline 10 & Denmark & 0.3017 & $4.71 \%$ \\
\hline 11 & Switzerland (old) & 0.2700 & $4.21 \%$ \\
\hline 12 & Finland (old) & 0.2570 & $4.02 \%$ \\
\hline 13 & Germany (new) & 0.2536 & $3.96 \%$ \\
\hline 14 & Hong Kong & 0.2518 & $3.93 \%$ \\
\hline 15 & U.K. (unprot) & 0.2419 & $3.78 \%$ \\
\hline 16 & Luxembourg (new) & 0.2147 & $3.35 \%$ \\
\hline 17 & Belgium (new) & 0.2128 & $3.32 \%$ \\
\hline 18 & France & 0.2049 & $3.20 \%$ \\
\hline 19 & Norway (new) & 0.2049 & $3.20 \%$ \\
\hline 20 & Portugal & 0.1956 & $3.06 \%$ \\
\hline 21 & Thailand & 0.1925 & $3.01 \%$ \\
\hline 22 & Spain & 0.1533 & $2.40 \%$ \\
\hline 23 & Korea & 0.1271 & $1.99 \%$ \\
\hline 24 & Japan (old) & 0.1261 & $1.97 \%$ \\
\hline 25 & U.K. (prot) & 0.1260 & $1.97 \%$ \\
\hline 26 & Luxembourg (old) & 0.1075 & $1.68 \%$ \\
\hline 27 & Italy (new) & 0.0934 & $1.46 \%$ \\
\hline 28 & Belgium (old) & 0.0586 & $0.92 \%$ \\
\hline 29 & Brazil & 0.0304 & $0.48 \%$ \\
\hline 30 & Italy (old) & 0.0046 & $0.07 \%$ \\
\hline
\end{tabular}

Figure 2 shows the evolution of the coefficient of variation with time, for a benchmark policyholder, for the selected systems. Typically, the coefficient of variation starts at zero for the first policy year, increases until the best policyholders reach the maximum discount, then decreases until stationarity is reached. Figure 3 shows the coefficient of variation as a function of the claim frequency. 


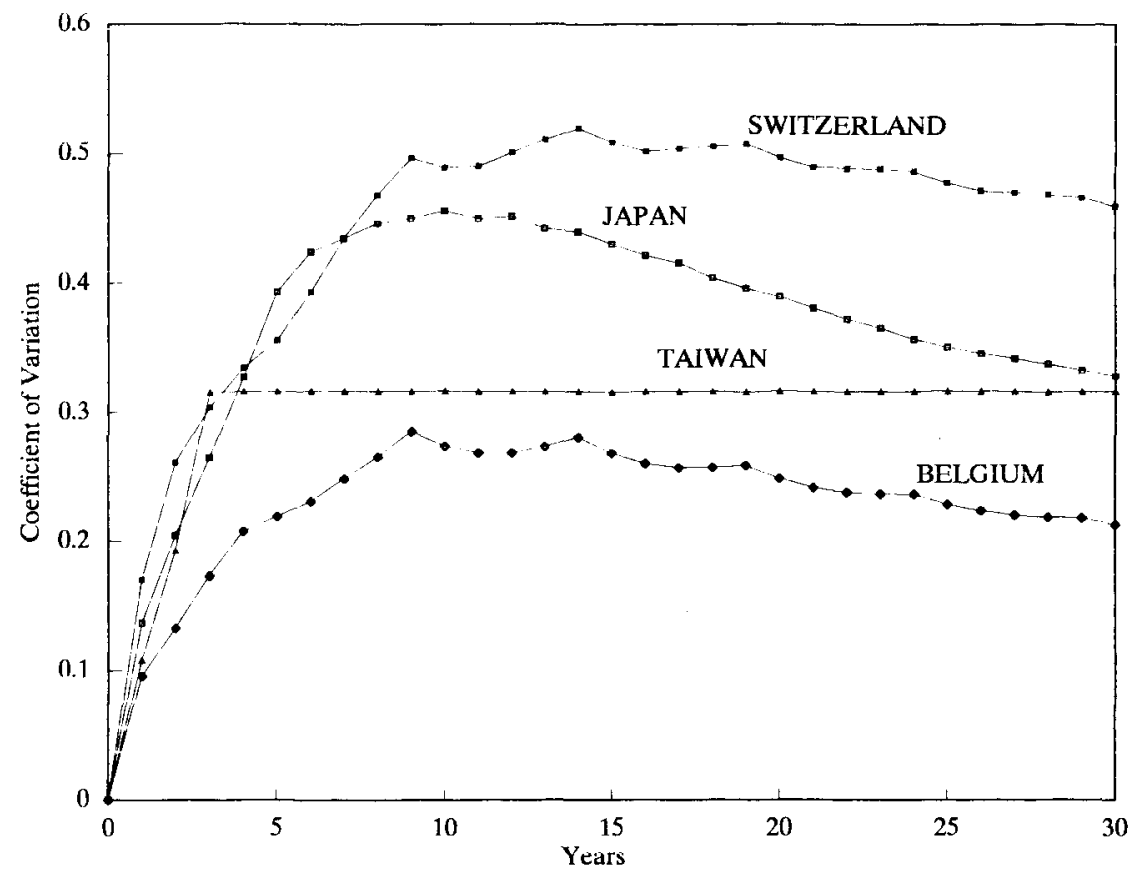

Flcilkl: 2. Evolution of coefficient of variation.

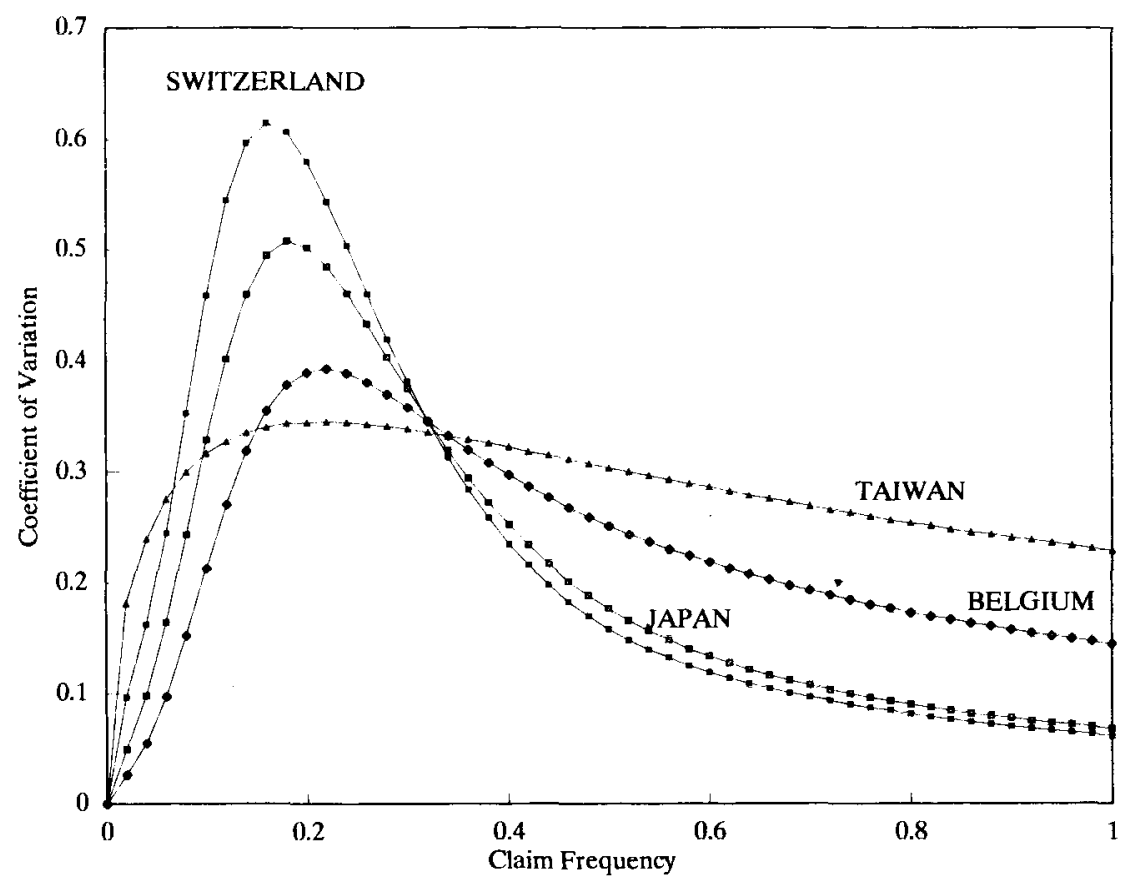

Figure 3. Coetficient of variation. 


\section{Tool \#3 :The efficiency of the bonus-malus system}

Consider two policyholders, one with a claim frequency of 0.10 , the other with a $\lambda$ of 0.11 . Over a long period of time, the second driver should pay $10 \%$ more premiums than the first. A BMS with this property is called perfectly efficient. In practice, however, the mean premium increase will in most cases be much lower than $10 \%$. If the increase is, say, $2 \%$ instead of $10 \%$, the system's efficiency is said to be $20 \%$. Denoting $P(\lambda)$ the mean stationary premium for a claim frequency $\lambda$, the efficiency $\mu(\lambda)$ of the BMS is defined as

$\mu(\lambda)=\frac{d P(\lambda) / P(\lambda)}{d \lambda / \lambda}$

It is the elasticity of the mean stationary premium with respect to the claim frequency: the relative increase of the premium, divided by the relative increase of the claim frequency. It measures the response of the system to a change in the claim frequency. This concept was first introduced in actuarial science by LoIMARANTA (1972).

Ideally, the efficiency should be close to 1 for the most common values of $\lambda$. Table 4 indicates the efficiency of all systems for a policyholder with claim

TABLE 4

EFFICIENCY

\begin{tabular}{rlc}
\hline \hline Rank & \multicolumn{1}{c}{ Country } & Efficiency \\
\hline 1 & Switzerland (new) & 0.449 \\
2 & Finland (new) & 0.403 \\
3 & Sweden & 0.298 \\
4 & Netherlands & 0.275 \\
5 & Norway (old) & 0.263 \\
6 & Germany (new) & 0.257 \\
7 & Kenya & 0.237 \\
8 & Japan (new) & 0.232 \\
9 & Switzerland (old) & 0.208 \\
10 & France & 0.200 \\
11 & Belgium (new) & 0.195 \\
12 & Finland (old) & 0.194 \\
13 & Luxembourg (new) & 0.183 \\
14 & Malaysia & 0.165 \\
15 & Denmark & 0.165 \\
16 & Taiwan & 0.136 \\
17 & Hong Kong & 0.133 \\
18 & U.K. (unprotected) & 0.129 \\
19 & Norway (new) & 0.127 \\
20 & Portugal & 0.111 \\
21 & Thailand & 0.081 \\
22 & Spain & 0.079 \\
23 & Korea & 0.078 \\
24 & Italy (new) & 0.063 \\
25 & Luxembourg (old) & 0.058 \\
26 & Japan (old) & 0.052 \\
27 & U.K. (protected) & 0.051 \\
28 & Belgium (old) & 0.024 \\
29 & Brazil (old) & 0.011 \\
30 & Italy (old) & 0.001 \\
\hline & & \\
\hline
\end{tabular}


frequency 0.10 . On top of the list are countries (Switzerland, Finland, The Netherlands, and Belgium) that have recently modified their BMS, by adopting tougher transition rules. Figure 4 shows the efficiency of the selected systems as a function of $\lambda$.

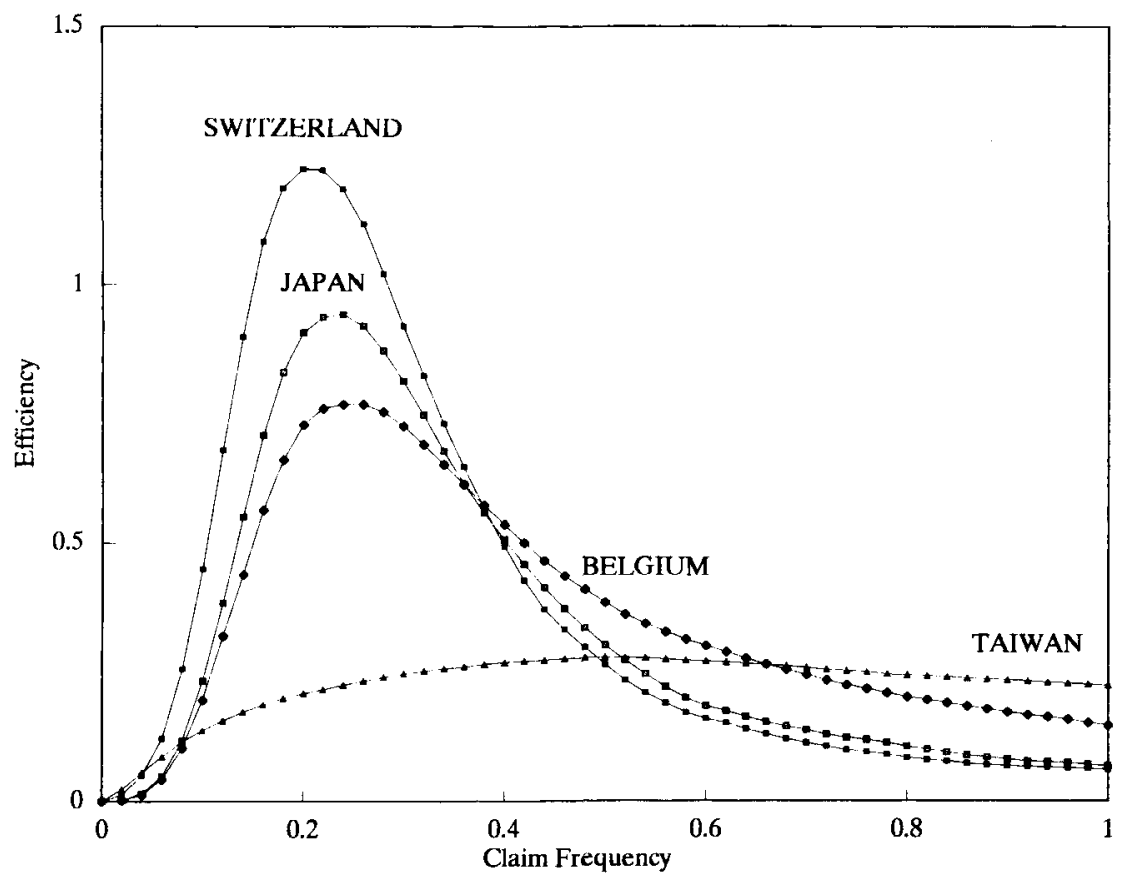

Figure 4. Efficiency.

\section{Tool \#4: The average optimal retention}

A well-known side-effect of BMS is the "hunger for bonus", the tendency of policyholders to pay small claims themselves, and not to report them to their carrier, in order to avoid future premium increases. A severe BMS will of course lead to a large bonus hunger inducement.

The optimal hunger for bonus associated with each BMS can be calculated using an algorithm based on dynamic programming (LEMAIRE, 1985, chapter 18). For each class of the system, the algorithm computes the optimal retention level, the level under which it is the policyholder's interest to not report a claim. Calculations require the following input:

(i) A discount factor, to compare present payments (the claim indemnified) with future savings (surcharges avoided). This factor includes not only inflation, but also policyholders' personal characteristics such as income increase anticipation and impatience rate. The selected factor was 0.90 ; 
(ii) A loss distribution. Since bodily injury claims have to be reported to the police and the insurer, a property damage only distribution should be used here. The 1989 Taiwanese property damage loss distribution can be accurately fitted by a Log-normal distribution, with parameters $\mu=8.7876$ and $\sigma^{2}=1.3569$. Since five years have elapsed since 1989, and since Taiwanese loss amounts are probably below worldwide averages, a $60 \%$ inflation factor was applied. It increases $\mu$ to $8.7876+\ln (1.60)=9.2576$, while leaving $\sigma^{2}$ unchanged;

(iii) A claim frequency, set at $10 \%$; and

(iv) A conversion factor, that enables the comparison of widely different BMS, and premiums expressed in many different currencies. Since the class at level 100 is situated at quite different positions, premium levels were rescaled by a multiplicative factor, in such a way that the average premium collected, if all claims are reported, is the same for each country. The basic units of Table 5 are such that the average collected premium, using an expense ratio of $40 \%$ of the

TABLE 5

AVERAGE OPTIMAL RETENTIONS

\begin{tabular}{|c|c|c|c|}
\hline \multirow[b]{2}{*}{ Rank } & \multirow[b]{2}{*}{ Country } & \multicolumn{2}{|c|}{ Average optimal retention } \\
\hline & & (Basic units) & $\begin{array}{c}\text { (Percentage of } \\
\text { average premium) }\end{array}$ \\
\hline 1 & Taiwan & 10,879 & $315.92 \%$ \\
\hline 2 & Kenya & 6,959 & $202.08 \%$ \\
\hline 3 & Finland (new) & 6,882 & $199.84 \%$ \\
\hline 4 & Norway (old) & 6,641 & $192.85 \%$ \\
\hline 5 & Switzerland (new) & 6,406 & $186.03 \%$ \\
\hline 6 & Sweden & 5,873 & $170.26 \%$ \\
\hline 7 & Netherlands & 5,799 & $168.40 \%$ \\
\hline 8 & Germany (new) & 5,451 & $158.29 \%$ \\
\hline 9 & Malaysia & 5,032 & $146.12 \%$ \\
\hline 10 & Finland (old) & 4,915 & $142.74 \%$ \\
\hline 11 & Portugal & 4,815 & $139.83 \%$ \\
\hline 12 & Denmark & 4,431 & $128.58 \%$ \\
\hline 13 & Hong Kong & 3,823 & $111.01 \%$ \\
\hline 14 & U.K. (unprotected) & 3,818 & $110.88 \%$ \\
\hline 15 & Switzerland (old) & 3,749 & $108.87 \%$ \\
\hline 16 & Norway (new) & 3,300 & $95.83 \%$ \\
\hline 17 & Belgium (new) & 3,001 & $87.14 \%$ \\
\hline 18 & Luxembourg (new) & 2,886 & $83.81 \%$ \\
\hline 19 & Japan (new) & 2,791 & $81.04 \%$ \\
\hline 20 & Thailand & 2,624 & $76.20 \%$ \\
\hline 21 & France & 2,524 & $73.28 \%$ \\
\hline 22 & Spain & 2,384 & $69.21 \%$ \\
\hline 23 & Korea & 2,145 & $62.28 \%$ \\
\hline 24 & Luxembourg (old) & 1,442 & $41.87 \%$ \\
\hline 25 & U.K. (protected) & 1,393 & $40.45 \%$ \\
\hline 26 & Belgium (old) & 1,286 & $37.34 \%$ \\
\hline 27 & Italy (new) & 1,181 & $34.28 \%$ \\
\hline 28 & Japan (old) & 712 & $20.68 \%$ \\
\hline 29 & Brazil & 370 & $10.74 \%$ \\
\hline 30 & Italy (old) & 19 & $0.55 \%$ \\
\hline
\end{tabular}


gross premium, is $3,443.6$. The knowledge of the average premium effectively collected in each country would then enable the calculation of optimal retentions in that country's currency. Table 5 ranks all systems according to the average optimal retention: the optimal retention for each class is weighted by its stationary class probability. Figures are provided both in basic units and in percentages of the average premium.

\section{An Index OF TOUGHNESS}

All four measures defined in Section 2 can be used to evaluate the "mildness" or "toughness" of a BMS. A system that penalises claims heavily will exhibit high RSAL, coefficient of variation of premiums, efficiency, and optimal retentions. These four measures, presented in Tables 1, 3, 4 and 5 for a benchmark policyholder, are however highly positively correlated, as shown in Table 6.

TABLE 6

Correlations betweEn the four measures of tOUghness

\begin{tabular}{lcrrr}
\hline \hline & RSAL & Coef. of variation & Efficiency & Average retention \\
\hline RSAL & 1 & .4748 & .3167 & .4813 \\
CV & & 1 & .9009 & .8378 \\
Efficiency & & & 1 & .6853 \\
Retention & & & 1 \\
\hline
\end{tabular}

Principal components analysis was used to summarise these data. The first principal component, or factor, explains $72.60 \%$ of the total variance, the second $18.71 \%$. Correlations between the first two factors and the four variables are indicated in Table 7.

TABLE 7

Factor Pattern - Correlations betweEn variables and Factors

\begin{tabular}{lcc}
\hline \hline & Factor 1 & Factor 2 \\
\hline RSAL & .6155 & -.7777 \\
Coef of variation & .9673 & -.1591 \\
Efficiency & .8837 & -.3428 \\
Average retention & .8993 & -.0243 \\
\hline
\end{tabular}

The first principal component is heavily correlated with efficiency, average retention, and the coefficient of variation. It is less correlated with RSAL. It can clearly be used as a measure of the toughness of a BMS, with the coefficient of variation as the best substitute variable for this index. Standardized factor scores for all 30 systems are provided in Table 8 . They rank all systems according to "toughness". Obviously, this ranking does not imply any judgment about the 
TABLE 8

FIRST FACTOR SCORES FOR ALL SYSTEMS

A measure of toughness

\begin{tabular}{|c|c|c|}
\hline Rank & Country & Factor score \\
\hline 1 & Switzerland (new) & 1.7917 \\
\hline 2 & Finland (new) & 1.7794 \\
\hline 3 & Kenya & 1.6942 \\
\hline 4 & Sweden & 1.2791 \\
\hline 5 & Taiwan & 1.1585 \\
\hline 6 & Norway (old) & 1.0974 \\
\hline 7 & Netherlands & 1.0610 \\
\hline 8 & Malaysia & 0.7948 \\
\hline 9 & Germany (new) & 0.5044 \\
\hline 10 & Finland (old) & 0.3427 \\
\hline 11 & Japan (new) & 0.2710 \\
\hline 12 & Denmark & 0.1912 \\
\hline 13 & Switzerland (old) & 0.1060 \\
\hline 14 & Hong Kong & 0.0100 \\
\hline 15 & U.K. (unprotected) & -0.0683 \\
\hline 16 & Spain & -0.1116 \\
\hline 17 & Portugal & -0.1339 \\
\hline 18 & Belgium (new) & -0.1604 \\
\hline 19 & Luxembourg (new) & -0.2831 \\
\hline 20 & France & -0.2886 \\
\hline 21 & Norway (new) & -0.3934 \\
\hline 22 & Thailand & -0.4754 \\
\hline 23 & U.K. (protected) & -0.8170 \\
\hline 24 & Korea & -0.9310 \\
\hline 25 & Luxembourg (old) & -1.1475 \\
\hline 26 & Italy (new) & -1.2003 \\
\hline 27 & Japan (old) & -1.2102 \\
\hline 28 & Belgium (old) & -1.4146 \\
\hline 29 & Brazil & -1.6210 \\
\hline 30 & Italy (old) & -1.8248 \\
\hline
\end{tabular}

quality of the systems. "Tough" is not to be considered as a synonym of "good" (or "bad"). Also, the rankings could have been somewhat different, had another benchmark claim frequency been selected.

Assuming that factor scores are normally distributed, a percentile on the standard normal distribution can be assigned to each system. For instance, the new Swiss system has a factor score situated 1.7917 standard deviations to the right of the mean. That corresponds to percentile 96.36 in the "universe" of BMS.

Factor scores are computed by the formula

$$
\begin{aligned}
\mathrm{SCORE}= & 0.26255 \times\left(\frac{\mathrm{EFF}-0.16193}{0.10769}\right)+0.26719 \times\left(\frac{\mathrm{RET}-3784.37}{2382.47}\right)+ \\
& +0.28739 \times\left(\frac{\mathrm{CV}-0.23087}{0.11398}\right)+0.18086 \times\left(\frac{\mathrm{RSAL}-7.4757}{7.2557}\right)
\end{aligned}
$$


That formula can be applied to rank any BMS not considered among the 30 analyzed here. For instance, the BMS in force in Germany in the early 1980s was not used in the construction of the above formula. It can nevertheless be positioned on Table 8 . It has a RSAL of $1.74 \%$, an efficiency of 0.163 , an average retention of 2900 , and a coefficient of variation of 0.1865 . Its factor score is evaluated at -0.3530 , which ranks this system 21 st on our Index of Toughness.

From Table 7, and the above formula, it is apparent that the RSAL is a mediocre tool to evaluate toughness. This is probably due to the fact that it is strongly influenced by the premium for the upper class, a class which is sparsely populated for the sophisticated systems. Alternative definitions of the RSAL could eliminate the influence of the classes with low occupation, at the expense of some arbitrariness. This would most probably result in a higher ranking of systems with many classes like the Belgian and the Swiss BMS.

An important remark is that the coefficient of variation is very close to the first principal component as a measure of the toughness of a BMS, since the correlation between the two is 0.9673 . Calculating the value of the Index of Toughness necessitates the computation of the values taken by the four tools, and their weighted average. Using the coefficient of variation as an alternate measure is much simpler and loses little in accuracy. The rank correlation between the two measures (Tables 3 and 8 ) is 0.9653 .

The most striking conclusion of the study of Table 8 is the position of the second-generation BMS. With the exception of Norway, all the countries that recently changed their system made it much tougher. Switzerland jumps from the 13 th to the 1 st rank, Finland from the 10th to the 2nd, Japan from the 27 th to the 11 th, etc.

\section{Comments}

\subsection{Belgium}

The old Belgian system, in force since 1971, exemplified the problems faced by insurers using a mild BMS : a strong clustering of policies in the high-discount classes. With only a two-class penalty for the first claim, the system was in fact designed for an average claim frequency of $1 / 3$. The much lower claims frequencies observed since the 1974 first oil shock created an increasing lack of financial balance, with over $75 \%$ of the policyholders in one of the three lowest classes in 1983 , and less than $1 \%$ of insureds in the malus zone. For instance, one company allowed BEF 713 millions in maluses in 1983, while recovering only 3 millions in maluses, thus producing an average discount of $32.84 \%$. This led the Professional Union of Insurance Companies to set up a study group and suggest a new system to the regulatory authorities (see LEMAIRE, 1988b). The new system was implemented in 1992. It penalises the first claim by 4 classes.

The new system has a special rule, that no policyholder can be in the malus zone after 4 consecutive claim-free years. This makes the BMS non-markovian, as it requires insurers to memorise the past behaviour of the policyholders for three years. The study of the BMS necessitates the subdivision of several classes into four 
sub-classes, adding a digit specifying the number of consecutive claim-free years (see LEMAIRE, 1985, chapter 17, for a description of the procedure). The impact of the special transition rule is evidenced in Table 9; a driver in class 18.0 (who had an accident last year) has an optimal retention of $288.16 \%$ of the average premium. This retention increases to $457.52 \%$ for an insured in class 18 with three claim-free years.

TABLE 9

OPTIMAL RETENTIONS - BELGIAN BMS

\begin{tabular}{lccc}
\hline \hline Class & Optimal retention & Class & Optimal retention \\
\hline 0 & $38.41 \%$ & 16.6 & $254.05 \%$ \\
1 & $56.50 \%$ & 16.3 & $305.99 \%$ \\
2 & $76.59 \%$ & 17.7 & $252.17 \%$ \\
3 & $98.26 \%$ & 17.2 & $296.85 \%$ \\
4 & $117.80 \%$ & 17.3 & $360.03 \%$ \\
5 & $137.34 \%$ & 18.0 & $288.16 \%$ \\
6 & $156.05 \%$ & 18.1 & $326.98 \%$ \\
7 & $174.03 \%$ & 18.2 & $382.01 \%$ \\
& & 18.3 & $457.52 \%$ \\
8 & $190.40 \%$ & 19.0 & $257.56 \%$ \\
9 & $208.83 \%$ & 19.1 & $304.64 \%$ \\
10 & $224.98 \%$ & 19.2 & $369.69 \%$ \\
11 & $239.38 \%$ & 19.3 & $457.52 \%$ \\
12 & $254.56 \%$ & 20.0 & $228.29 \%$ \\
13 & $273.65 \%$ & 20.1 & $283.74 \%$ \\
14 & $285.46 \%$ & 20.2 & $359.28 \%$ \\
15 & $269.02 \%$ & 21.0 & $196.03 \%$ \\
& & 21.1 & $260.11 \%$ \\
& & 22 & $147.31 \%$ \\
\hline
\end{tabular}

The impact of the stronger transition rules is evident in our overall ranking. Belgium moves from the 28 th to the 18 th place. Still, the new system still has a slightly negative score on the first factor. The new BMS has to be classified as "average".

\subsection{Japan}

Up to April 1993, Japanese insurers used a BMS that was unique in the world in the sense that any claim involving bodily injury was penalised as two property damage claims. (Korea is the only other country where penalties depend on claim severity). That system was extremely mild, ranking 27 th in the "toughness" scale. Once a policyholder had reached the highest discount class, his first claim was not penalised, as the premium level remained at 40 . Even two claims in a single year only raised the premium level from 40 to 45 . As the penalty for a property damage claim was two classes only, the system was "designed" for claim frequencies around $1 / 3$. The efficiency was extremely high for claims frequencies around 0.33 , culminating at 1.165 for $\lambda=0.29$. The old Japanese BMS was a rare example of an "over-efficient" system, for specific values of $\lambda$.

The transition rules are now tougher, and the BMS ranks in 11 th place. Table 10 shows that optimal retentions have considerably increased in all but the top upper 
classes. The simulation predicts a somewhat better spread of policies among the classes, with $61 \%$ of all drivers (instead of $74 \%$ ) eventually occupying class 1 .

TABLE 10

OPTIMAL RETENTIONS - JAPANESE BMS

\begin{tabular}{lcccc}
\hline \hline Class & $\begin{array}{c}\text { Optimal } \\
\text { retention } \\
\text { (old) }\end{array}$ & $\begin{array}{c}\text { Stationary class } \\
\text { probability } \\
\text { (old) }\end{array}$ & $\begin{array}{c}\text { Optimal } \\
\text { retention } \\
\text { (new) }\end{array}$ & $\begin{array}{c}\text { Stationary class } \\
\text { probability } \\
\text { (new) }\end{array}$ \\
\hline 1 & $5.80 \%$ & .7409 & $20.13 \%$ & .6095 \\
2 & $16.13 \%$ & .0794 & $39.65 \%$ & .0608 \\
3 & $34.95 \%$ & .0879 & $68.36 \%$ & .0714 \\
4 & $64.33 \%$ & .0333 & $113.84 \%$ & .0865 \\
5 & $107.37 \%$ & .0283 & $169.00 \%$ & .0382 \\
6 & $159.73 \%$ & .0116 & $230.80 \%$ & .0306 \\
7 & $216.07 \%$ & .0084 & $294.55 \%$ & .0317 \\
8 & $265.54 \%$ & .0040 & $350.40 \%$ & .0205 \\
9 & $309.07 \%$ & .0028 & $399.33 \%$ & .0141 \\
10 & $347.46 \%$ & .0014 & $437.20 \%$ & .0103 \\
11 & $380.76 \%$ & .0009 & $474.27 \%$ & .0085 \\
12 & $409.51 \%$ & .0005 & $496.78 \%$ & .0067 \\
13 & $423.46 \%$ & .0003 & $508.49 \%$ & .0042 \\
14 & $427.26 \%$ & .0002 & $383.44 \%$ & .0030 \\
15 & $281.77 \%$ & .0001 & $252.43 \%$ & .0024 \\
16 & $137.39 \%$ & .0001 & $123.02 \%$ & .0016 \\
Average & $20.68 \%$ & & $81.04 \%$ & \\
\hline
\end{tabular}

\subsection{Switzerland}

In January of 1990, Swiss insurers modified their BMS, keeping all of its former characteristics while adding a penalty class for each claim. This made the Swiss system the toughest system in the world. The impact of the change in the transition rules on optimal retentions and on the stationary distribution of policyholders is shown in Table 11. The decision to enforce a strong BMS was probably influenced by the fact that Swiss insurers are only allowed to use one a priori classification variable (the engine displacement, with over $70 \%$ of all vehicles in one class), as well as a deductible for young drivers.

\subsection{Taiwan}

Taiwan has adopted a simple system. Its unique characteristic (shared with Thailand) is that all surcharges are erased after a single claim-free year, and that all discounts are eliminated following a single claim. As a result, optimal retentions are very high in all classes, and Taiwan ranks first in average optimal retention. (For most other countries, retentions can be extremely high, but in sparsely-populated high-malus classes. Low retentions in the best classes results in a lower weighted average retention). 
TABLE 11

OPTIMAL RETENTIONS - SWISS BMS

\begin{tabular}{rcccc}
\hline \hline Class & $\begin{array}{c}\text { Optimal } \\
\text { retention } \\
\text { (old) }\end{array}$ & $\begin{array}{c}\text { Stationary class } \\
\text { probability } \\
\text { (old) }\end{array}$ & $\begin{array}{c}\text { Optimal } \\
\text { retention } \\
\text { (new) }\end{array}$ & $\begin{array}{c}\text { Stationary class } \\
\text { probability } \\
\text { (new) }\end{array}$ \\
\hline 0 & $68.87 \%$ & .6512 & $98.12 \%$ & .5396 \\
1 & $104.07 \%$ & .0648 & $136.14 \%$ & .0489 \\
2 & $135.67 \%$ & .0781 & $170.16 \%$ & .0535 \\
3 & $164.42 \%$ & .0972 & $200.87 \%$ & .0700 \\
4 & $190.84 \%$ & .0250 & $235.40 \%$ & .1084 \\
5 & $223.00 \%$ & .0220 & $273.13 \%$ & .0255 \\
6 & $259.94 \%$ & .0224 & $314.14 \%$ & .0230 \\
7 & $300.96 \%$ & .0156 & $358.08 \%$ & .0207 \\
8 & $346.17 \%$ & .0054 & $404.68 \%$ & .0264 \\
9 & $386.78 \%$ & .0045 & $446.43 \%$ & .0314 \\
10 & $423.44 \%$ & .0047 & $490.69 \%$ & .0079 \\
11 & $464.83 \%$ & .0039 & $537.17 \%$ & .0064 \\
12 & $510.23 \%$ & .0009 & $585.85 \%$ & .0060 \\
13 & $558.85 \%$ & .0010 & $636.41 \%$ & .0090 \\
14 & $610.66 \%$ & .0013 & $681.26 \%$ & .0100 \\
15 & $656.67 \%$ & .0008 & $716.85 \%$ & .0023 \\
16 & $688.55 \%$ & .0002 & $750.10 \%$ & .0020 \\
17 & $719.47 \%$ & .0003 & $778.53 \%$ & .0022 \\
18 & $746.42 \%$ & .0003 & $629.71 \%$ & .0028 \\
19 & $565.56 \%$ & .0002 & $476.50 \%$ & .0023 \\
20 & $381.43 \%$ & .0001 & $321.01 \%$ & .0009 \\
21 & $189.38 \%$ & .0001 & $159.38 \%$ & .0009 \\
Average & $108.87 \%$ & & $186.03 \%$ & \\
\hline & & & & \\
\hline & & & & \\
\hline
\end{tabular}

TABLE 12

Optimal RETENTIONS - TAIWANESE BMS

\begin{tabular}{lcc}
\hline Class & Optimal retention & Stationary class probability \\
\hline 1 & $339.72 \%$ & .7403 \\
2 & $339.72 \%$ & .0782 \\
3 & $223.63 \%$ & .0862 \\
4 & $195.00 \%$ & .0000 \\
5 & $195.00 \%$ & .0906 \\
6 & $195.00 \%$ & .0046 \\
7 & $195.00 \%$ & .0001 \\
8 & $195.00 \%$ & .0000 \\
9 & $195.00 \%$ & .0000 \\
Average & $315.92 \%$ & \\
\hline
\end{tabular}

Another consequence of the strong transition rules is the high variability of the premium for the policyholders with a low claim frequency $(\lambda<0.10)$, who constitute a majority (see Fig. 3).

On all other measures, Taiwan ranks about average. The overall ranking of the system is 5 th. The maximum efficiency of 0.278 is low, and is only obtained for a high value of the claim frequency $(\lambda=0.49)$. 


\section{REFERENCES}

Bowers, N., Hickman, J., Gerber, H., Jones, D. and Nesbitt, C. (1986) "Actuarial Mathematics". Society of Actuaries, Schaumburg, Hllinois.

Lemaire, J. (1985) “Automobile Insurance: Actuarial Models". Kluwer, Boston.

Lemaire, J. (1988a) "A comparative Analysis of most European and Japanese Bonus-malus systems". J. of Risk and Insurance LV, 660-681.

Lemaire, J. (1988b) "Construction of the New Belgian Motor Third Party Tariff Structure". ASTIN Bulletin 18, 99-112.

LemaIRE, J. (1993) "Selecting a Fitting Distribution for Taiwanese Automobile Losses". Unpublished manuscript.

Loimaranta, K. (1972) "Some Asymptotic Properties of Bonus Systems". ASTIN Bulletin 6, $233-245$.

Neuhaus, W. (1988) "A bonus-malus system in automobile insurance". Insurance: Mathematics \& Economics 7, 103-112.

\section{APPENDIX}

\section{DESCRIPTION OF ALL BONUS-MALUS SYSTEMS}

This appendix provides a summary description of all BMS analysed in this paper. For each BMS, we provide the number of classes, all premium levels, the starting levels, and a short description of the transition rules: the number of classes decreased following a claim-free year, and the number of classes increased following claims. Special rules and assumptions are mentioned. A perfectly accurate description of all BMS would necessitate a full presentation of the transition table, and require many more pages. The obvious regulatory trend in most countries is towards more freedom. So it is probable that, by the time this article is published, the BMS described here will co-exist with many other systems.

\section{1-2. BELGIUM —Old system (1971)}

* Number of classes: 18

* Levels : 60, 65, 70, 75, 80, 85, 90, 95, 100, 100, 105, 110, 115, 120, 130, 140, 160,200

* Starting level : 85 for pleasure use and commuting, 100 for business use

* Claim-free: - 1. Cannot be above level 100 after 4 consecutive claim-free years.

First claim: +2 . Subsequent claims : +3

New system (1992)

* Number of classes : 23

* Levels : 54, 54, 54, 57, 60, 63, 66, 69, 73, 77, 81, 85, 90, 95, 100, 105, 111, 117, $123,130,140,160,200$

* Starting level : 85 for pleasure use and commuting, 100 for business use

* Claim-free: - 1. Cannot be above level 100 after 4 consecutive claim-free years.

First claim : +4 . Subsequent claims : +5 


\section{BRAZIL}

* Number of classes: 7

* Levels: $65,70,75,80,85,90,100$

* Starting level: 100

* Claim-free : -1

Each claim : +1

\section{DENMARK}

* Number of classes : 10

* Levels: $30,40,50,60,70,80,90,100,120,150$

* Starting level : 100

* Claim-free : -1

Each claim: +2

\section{5-6. FINLAND - Old System}

* Number of classes: 14

* Levels: $40,50,50,50,50,60,60,70,80,100,110,120,130,150$

* Starting level : 120

* Claim-free : -1

First claim: from +6 (lowest classes) to +1 (highest classes)

Subsequent claims: +3

New system

* Number of classes : 17

* Levels: $30,35,40,45,50,55,60,65,70,75,80,85,90,95,100,100,100$

* Starting level : lowest 100

* Claim-free : - 1

First claim: +3 or +4 . Subsequent claim : +4 or +5

\section{FRANCE}

* Number of classes : 351

* Levels : all integers from 50 to 350

* Starting level : 100.

* Claim-free: $5 \%$ reduction. Cannot be above level 100 after 2 consecutive claim-free years.

Each claim : $25 \%$ increase, $12.5 \%$ if shared responsibility.

* A recent modification is that the first claim of a policyholder who was at the lowest level for at least 3 years is not penalised.

\section{GERMANY - Old System}

* Number of classes: 18

* Levels : 40, 40, 40, 40, 40, 45, 50, 55, 60, 65, 70, 85, 100, 125, 175, 175, 200, 200 
* Starting level: 175, or 125 if licensed for at least three years

* Claim-free : -1 or to level 100, if more favourable

Each claim: from +1 or +2 (highest levels) to +4 or +5 (lowest levels)

9. New System

* Number of Classes : 22

* Levels: $30,35,35,35,40,40,40,40,40,45,45,50,55,60,65,70,85,100$, $125,155,175,200$

* Starting level : 175 or 125 , depending on experience and other cars in the same household.

* Claim-free: -1 , except in the upper classes.

Each claim: from +1 (upper classes) to +9 (lowest class)

\section{HONG KONG}

* Number of classes: 6

* Levels : $40,50,60,70,80,100$

* Starting level : 100

* Claim-free : - 1

First claim: +2 or +3 . Subsequent claims : all discounts lost

\section{1-12. ITALY - Old system}

* Number of classes: 13

* Levels : 70, 70, 70, 75, 80, 85, 92, 100, 115, 132, 152, 175, 200

* Starting level : 115

* Claim-free : -1

Each claim : +1

New System (1991)

* Number of classes: 18

* Levels : 50, 53, 56, 59, 62, 66, 70, 74, 78, 82, 88, 94, 100, 115, 130, 150, 175 , 200

* Starting level: 115

* Claim-free : -1

First claim: +2 . Subsequent claim $:+3$

\section{3-14. JAPAN}

* Number of classes: 16

* Levels : 40, 40, 40, 42, 45, 50, 60, 70, 80, 90, 100, 110, 120, 130, 140, 150

* Starting level : 100

* Claim-free : -1 
Old System (1984)

Each claim: +2 Property Damage, +4 Bodily Injury

New System (1993).

Each claim: +3

* $12.5 \%$ of all claims have bodily injury implications.

\section{KENYA}

* Number of classes : 7

* Levels: $40,50,60,70,80,90,100$

* Starting level : 100

* Claim-free: -1

Each claim: all discounts lost

\section{KOREA}

* Number of classes : 37

* Levels: $40,45,50,55,60, \ldots, 210,215,220$

* Starting level: 100

* Claim-free: the premium level generally decreases by 10 . Moving down is however only allowed after 3 claim-free years. The policy cannot be above level 100 after 3 claim-free years.

Each claim: Property damage claims are penalised by 0.5 or 1 penalty point, depending on the cost. Bodily injury claims are penalised by 1 to 4 points, depending on the type of injury. Serious offenses are assessed supplementary points, up to 3 . The premium increase is 10 levels per penalty point, with a few exceptions.

* As data concerning the distribution of injuries were not available, it was assumed that all claims were penalised by one point, by far the most probable value.

\section{7-18. LUXEMBOURG - Old system}

* Number of classes: 22

* Levels : 50, 55, 60, 65, 70, 75, 80, 85, 90, 100, 100, 105, 110, 115, 120, 130, $140,160,180,200,225,250$

* Starting level : 100

* Claim-free: -1 . Cannot be above level 100 after 4 consecutive claim-free years

Each claim: +2

New system

* Two new classes, at levels 47.5 and 45 , have been added.

* Each claim : + 3 


\section{MALAYSIA - SINGAPORE}

* Number of classes: 6

* Levels: 45, 55, 61.67, 70, 75, 100

* Starting level : 100

* Claim-free : - 1

Each claim : all discounts lost

\section{THE NETHERLANDS (1981)}

* Number of classes: 14

* Levels: 30, 32.5, 35, 37.5, 40, 45, 50, 55, 60, 70, 80, 90, 100, 120

* Starting level : 70 to 100 , depending on age and annual mileage

* Claim-free : -1

Each claim : +3 to +5

\section{1-22. NORWAY - Old system}

* Number of classes: infinite

* Levels : $30,40,50,60,70, \ldots$

* Starting level : 100

* Claim-free: -1 or level 120 , if more favourable

First claim: +2 (highest levels) or +3 (3 lowest levels).

Subsequent claims : +2

New system

Several BMS currently coexist. The following system was launched in 1987 by a leading company (see NeuHaus, 1988)

* Number of classes : infinite

* Levels: all integers from 25 up

* Starting level : 80, for drivers aged at least 25 insuring their privately owned vehicle. 100 for all others.

* Claim-free : $13 \%$ discount.

Each claim: fixed amount premium increase (NOK 2,500 in 1988). The penalty cannot however exceed $50 \%$ of the basic premium. The penalty is reduced by half for the drivers who have had between five and nine consecutive claim-free years at level 25 , for their first claim. It is waived for drivers who have had at least ten consecutive years at the 25 level, for their first claim. An extra deductible is enforced if the claimant is at a higher level than 80 , prior to the claim.

\section{PORTUGAL}

* Number of classes: 6

* Levels : 70, 100, 115, 130, 145, 200

* Starting level : 100 
* Claim-free : -1 after two-consecutive claim-free years

Each claim : +1

24. SPAIN

* Number of classes: 5

* Levels : 70, 80, 90, 100, 100

* Starting level: highest 100

* Claim-free : - 1

Each claim: all discounts lost

* The use of this BMS has now been discontinued by most insurers, as complete rating freedom now exists.

\section{SWEDEN}

* Number of classes: 7

* Levels : 25, 40, 50, 60, 70, 80, 100

* Starting level : 100

* Claim-free: -1 . Level 25 is only awarded after 6 consecutive claim-free years.

Each claim : +2

* A fixed premium of SEK 100 (about $10 \%$ of the average premium) is not affected by the BMS.

\section{6-27. SWITZERLAND}

* Number of classes: 22

* Levels : 45, 50, 55, 60, 65, 70, 75, 80, 90, 100, 110, 120, 130, 140, 155, 170, $185,200,215,230,250,270$

* Starting level : 100

* Claim-free : -1

Old system

Each claim : +3

New system (1990)

Each claim : +4

\section{TAIWAN}

* Number of classes: 9

* Levels : 50, 65, 80, 100, 110, 120, 130, 140, 150

* Starting level : 100

* Claim-free : -1 or to level 80 , if more favourable

Claims : if $k$ claims, to level $100+10 k$ 
29. THAILAND

* Number of classes: 7

* Levels : $60,70,80,100,120,130,140$

* Starting level: 100

* Claim-free : -1 or to level 80 , if more favourable First claim: to level 100. Two or more claims: to level 120 or +1 (least favourable)

\section{0-31. UNITED KINGDOM (Typical BMS)}

* Number of classes : 7

* Levels : $33,40,45,55,65,75,100$

* Starting level : 75

* Claim-free : -1

First claim: +3 (level 33$),+2$ (levels 40 and 45$),+1$

Subsequent claims: +2

* As British insurers enjoy complete tariff structure freedom, many BMS coexist. Many insurers have recently introduced "protected discount schemes": policyholders who have reached the maximum discount may elect to pay a surcharge, usually in the $[10 \%-20 \%]$ range, to have their entitlement to discount preserved in case of a claim. More than two claims in five years result in disqualification from the protected discount scheme. Both the protected and unprotected forms are analysed.

Jean Lemaire and Hongmin $Z_{1}$

Department of Insurance and Risk Management,

Wharton School, University of Pennsylvania,

3641 Locust Walk, Philadelphia, PA 19104-6218, U.S.A. 